\title{
Review \\ Bench-to-bedside review: Understanding the impact of resistance and virulence factors on methicillin-resistant Staphylococcus aureus infections in the intensive care unit
}

\author{
Lee P Skrupky ${ }^{1}$, Scott T Micek ${ }^{1}$ and Marin H Kollef ${ }^{2}$ \\ 1Department of Pharmacy, Barnes-Jewish Hospital, St Louis, MO 63110, USA \\ ${ }^{2}$ Department of Pulmonary and Critical Care Medicine, Washington University School of Medicine, St Louis, MO 63110, USA
}

Corresponding author: Marin H Kollef, mkollef@dom.wustl.edu

Published: 8 October 2009

Critical Care 2009, 13:222 (doi:10.1186/cc8028)

This article is online at http://ccforum.com/content/13/5/222

(c) 2009 BioMed Central Ltd

\begin{abstract}
Methicillin-resistant Staphylococcus aureus (MRSA) displays a remarkable array of resistance and virulence factors, which have contributed to its prominent role in infections of the critically ill. We are beginning to understand the function and regulation of some of these factors and efforts are ongoing to better characterize the complex interplay between the microorganism and host response. It is important that clinicians recognize the changing resistance patterns and epidemiology of Staphylococcus spp., as these factors may impact patient outcomes. Community-associated MRSA clones have emerged as an increasingly important subset of Staphyloccocus aureus and MRSA can no longer be considered as solely a nosocomial pathogen. When initiating empiric antibiotics, it is of vital importance that this therapy be timely and appropriate, as delays in treatment are associated with adverse outcomes. Although vancomycin has long been considered a firstline therapy for serious MRSA infections, multiple concerns with this agent have opened the door for existing and investigational agents demonstrating efficacy in this role.
\end{abstract}

Methicillin-resistant Staphylococcus aureus (MRSA) has proven to be a prominent pathogen in the ICU setting capable of causing a variety of severe infections. In the face of increasing antibiotic pressure, increased resistance and virulence has been noted to occur and recent research is helping us to better understand the complex interplay between the invading microorganism and the ensuing host immune response. This review will focus on the resistance mechanisms and virulence factors employed by MRSA, their associated impact on patient outcomes and current treatment options.

\section{Antibiotic resistance}

Methicillin-resistance in Staphylococcus species is encoded via the mecA gene, which results in production of penicillin- binding protein ( $\mathrm{PBP}) 2 \mathrm{~A}$, a penicillin binding protein with reduced affinity for $\beta$-lactams [1]. mec is part of a larger genomic element termed the Staphylococcal chromosomal cassette (SCCmec), which contains genes mediating antibiotic resistance. Up to eight types of SCCmec have now been reported in the literature [2] and the differences between these SCCmec types account for the primary differences between various MRSA clones. For example, SCCmec I, II, and III are larger and more difficult to mobilize and are most frequently present in hospital acquired (HA-MRSA) clones (USA 100 and 200). SCCmec IV is a smaller, easier to mobilize genetic element that is frequently present in community-associated MRSA (CA-MRSA; clones USA 300 and 400) [3]. It has been observed that CA-MRSA is effectively integrating into the health care environment and it is therefore increasingly less reliable to make this differentiation on the basis of acquisition location [4-7]. HA-MRSA and CA-MRSA clones are noted to display different resistance patterns as a result of their unique genetic elements. Compared with HA-MRSA, CA-MRSA isolates are more likely to be susceptible to non- $\beta$-lactam antibiotics, including trimethoprim-sulfamethoxazole (TMP-SMX), clindamycin, fluoroquinolones, gentamicin, erythromycin, and tetracyclines with geographic variability [7-9].

Increasing attention is being paid to the issue of reduced susceptibility and resistance of MRSA to vancomycin. Although vancomycin has long been considered a reliable agent for treatment of MRSA infections, isolates with intermediate (VISA) and full (VRSA) levels of resistance have been reported. The Clinical and Laboratory Standards Institute vancomycin minimum inhibitory concentration (MIC)

agr = accessory gene regulator; CA-MRSA = community-associated MRSA; CRBSI = catheter-related blood stream infection; HA-MRSA = hospital-acquired MRSA; hVISA = heteroresistant vancomycin intermediate $S$. aureus; MIC = minimum inhibitory concentration; MRSA = methicillinresistant Staphylococcus aureus; MSSA = methicillin-susceptible $S$. aureus; PBP = penicillin-binding protein; PVL = Panton-Valentine leukocidin; SCC $=$ Staphylococcal chromosomal cassette; TSST = toxic shock syndrome toxin; VISA = vancomycin intermediate $S$. aureus; VRSA $=$ vancomycin-resistant $S$. aureus. 
breakpoints for MRSA were last updated in 2006 and resulted in a lowering of the breakpoints as follows: susceptible, $\leq 2 \mu \mathrm{g} / \mathrm{ml}$; intermediate, 4 to $8 \mu \mathrm{g} / \mathrm{ml}$; resistant, $\geq 16 \mu \mathrm{g} / \mathrm{ml}$.

Vancomycin exerts its antibiotic activity by binding to the Dalanyl-D-alanine portion of cell wall precursors, which subsequently inhibits peptidoglycan polymerization and transpeptidation. High-level resistance is mediated via the vanA gene, which results in production of cell wall precursors (DAla-D-lac or D-Ala-D-Ser) with reduced affinity for vancomycin [10]. Intermediate level resistance (VISA) is believed to be preceded by the development of heteroresistant vancomycin intermediate $S$. aureus (hVISA) [11]. Heteroresistance is the presence of resistant subpopulations within a population of bacteria determined to be susceptible to the antibiotic tested. It is thought that exposure of such a heteroresistant MRSA population to low concentrations of vancomycin may kill the fully susceptible subpopulations and select for the resistant subpopulations. The mechanisms of heteroresistance are not fully elucidated, but are hypothesized to be due to a thickened cell wall and increased production of false binding sites [11]. The accessory gene regulator (agr; discussed in detail below) type and functionality may also play a role in the development of this type of resistance [12].

Reduced susceptibility to glycopeptides may also impact the susceptibility of MRSA to daptomycin. Several reports have found hVISA and VISA isolates to display resistance to daptomycin [13-15]. Daptomycin is a cyclic lipopetide that works by binding to the cell membrane to subsequently cause destabilization resulting in bactericidal activity. It is hypothesized that the thickened cell wall noted to occur in MRSA isolates with intermediate-level vancomycin resistance may result in sequestration of daptomycin. Additionally, reduced susceptibility has been documented to develop while on prolonged daptomycin therapy $[16,17]$.

Linezolid is a synthetic oxazolidinone that inhibits the initiation of protein synthesis by binding to the 23s ribosomal RNA and thereby preventing formation of the 70 s initiation complex. Although linezolid has generally remained a reliable antibiotic for MRSA infections, several occurrences of resistance have been observed $[18,19]$. The first report of resistance [18] from a clinical isolate was reported in 2001, about 15 months after the drug was introduced to the market. Upon analysis, the organism was found to have mutations in the DNA encoding a portion of the 23s ribosomal RNA (rRNA). Linezolid resistance has been identified more commonly among Staphylococcus epidermidis and Enterococcus species, but the possibility of linezolid resistance among MRSA should be kept in mind.

In vitro studies have reported tigecycline to be highly active against MRSA isolates that have been tested. No reports of resistance to clinical isolates have been reported to our knowledge, but the use of this agent for serious MRSA infections has been very limited. Quinupristin/dalfopristin has similarly been shown to be highly active in vitro against MRSA, but clinical isolates with resistance have been reported [20] and the use of this agent for serious MRSA infections has also been limited.

\section{Virulence factors for MRSA}

Virulence factors play an important role in determining the pathogenesis of MRSA infections. Colonization by MRSA is enhanced by biofilm formation, antiphagocytocic microcapsules, and surface adhesions [21]. Once an inoculum is established, $S$. aureus can produce a variety of virulence factors to mediate disease, including exoenzymes and toxins. Exoenzymes include proteases, lipases and hyaluronidases, which can cause tissue destruction and may facilitate spread of infection. The toxins that can be produced are numerous and include hemolysins, leukocidins, exfoliative toxins, Panton-Valentine leukocidin (PVL) toxin, toxic shock syndrome toxin (TSST-1), enterotoxins, and $\alpha$-toxin [21]. $S$. aureus also has a multitude of mechanisms to further elude and modulate the host immune response. Specific examples include inhibition of neutrophil chemotaxis via a secreted protein called chemotaxis inhibitory protein of staphylococci (CHIPS), resistance to phagocytosis via surface proteins (for example, protein A and clumping factor A (ClfA)), inactivation of complement via Staphylococcus complement inhibitor (SCIN), and production of proteins that confer resistance to lysozyme (for example, O-acetyltransferase) and antimicrobial peptides (for example, modified Dlt proteins and MprF protein) [22].

Various toxins have been associated with different clinical scenarios and clinical presentations [21]. For example, $\alpha$-toxin, enterotoxin, and TSST-1 are believed to lead to extensive cytokine production and a resulting systemic inflammatory response. Epidermolytic toxins $A$ and $B$ cause the manifestations of Staphylococcal scalded skin syndrome. PVL is most frequently associated with CA-MRSA and may play an important role in cavitary pneumonia and necrotizing skin and soft tissue infections, as discussed in the following section.

Expression of virulence factors is largely controlled by the agr [23]. Polymorphisms in agr account for the now five different types that have been identified. HA-MRSA isolates are most frequently agr group II, whereas CA-MRSA isolates are most frequently agr groups I and III. Another difference is that agr is functional in a majority of CA-MRSA isolates whereas agr may be dysfunctional in about half of HA-MRSA isolates [24]. When agr is active it generally results in upregulation of secreted factors and downregulation of cell surface virulence factors. This pattern of expression has been noted to occur during the stationary growth phase when studied in vitro and in animal models. During an exponential growth phase, upregulation of cell surface factors is increased and production of secreted factors is decreased. A recent study 
[25] sought to examine virulence gene expression in humans by measuring transcript levels of virulence genes in samples taken directly from children with active CA-MRSA skin and soft tissue infections (superficial and invasive abscesses). This analysis showed that genes encoding secretory toxins, including PVL, were highly expressed during both superficial and invasive CA-MRSA infections whereas surface associated protein A (encoded by spa) was only associated with invasive disease. It was also demonstrated that the virulence gene expression profiles measured from in vivo samples differed from those observed when the clinical isolates were exposed to purified neutrophils in vitro. This study therefore found some differences between in vitro and animal models when compared to this in vivo assessment and supports the hypothesis that the course of an MRSA infection can be altered in recognition of host-specific signals.

\section{The changing epidemiology and impact of resistance and virulence on outcomes}

The era of MRSA being exclusively a nosocomial pathogen is quickly fading. An epidemiologic study conducted in metropolitan areas throughout the United States found only $27 \%$ of MRSA sterile-site infections are of nosocomial origin [26]. Taking a closer look, of the $63 \%$ of patients presenting from the 'community', the majority had recent healthcare exposures, including hospitalization in the previous 12 months, residence in a nursing care facility, chronic dialysis, and presence of an invasive device at the time of admission. This group of patients deemed to have 'healthcare-associated, community-onset' infection most often harbor strains of MRSA associated with the hospital setting; however, crossover of the CA-MRSA clone into these patients is occurring in many healthcare centers [4-7].

Numerous studies have evaluated the impact methicillin resistance has on the outcome of patients infected with $S$. aureus. A meta-analysis of $31 \mathrm{~S}$. aureus bacteremia studies found a significant increase in mortality associated with MRSA bacteremia compared to methicillin-susceptible $S$. aureus (MSSA) bacteremia (pooled odds ratio 1.93, 95\% confidence interval 1.54 to $2.42 ; P<0.001)$. This finding remained evident when the analysis was limited to studies that were adjusted for potential confounding factors, most notably severity of illness [27]. Since this publication, several other investigations comparing MRSA and MSSA bacteremia have yielded similar results [28]. The higher attributable mortality associated with MRSA could be explained, in part, by significant delays in the administration of an antibiotic with anti-MRSA activity, particularly in patients presenting from the community. A single-center cohort study found only $22 \%$ of MRSA sterile-site infections cultured within the first 48 hours of hospital admission received an anti-MRSA antibiotic within the first 24 hours of culture collection, a factor that was independently associated with hospital mortality [29], and a significant contributor to hospital length of stay and costs [30].
In the majority of hospitals throughout the world, the antibiotic of choice for empiric therapy of suspected MRSA infection is vancomycin. However, just as the era of MRSA occurring only in the hospital setting has ended, so too might the automatic, empiric use of vancomycin in these situations. Increasingly it is being reported that MRSA infections with vancomycin MICs in the higher end of the 'susceptible' range (1.5 to $2 \mathrm{mcg} / \mathrm{ml}$ ) may be associated with higher rates of treatment failure compared to isolates with a MIC of $1 \mathrm{mcg} / \mathrm{ml}$ or less [31]. Additionally, a cohort analysis of MRSA bacteremia found vancomycin therapy in isolates with an MIC of $2 \mathrm{mcg} / \mathrm{ml}$ was associated with a 6.39 -fold increase in the odds of hospital mortality [32].

As the predominant genetic background of MRSA is transitioning from that of the hospital to community architecture (for example, clones USA 100 to USA 300) in hospitalized patients, so too might the severity of infection. Because of its epidemiologic association with CA-MRSA and severe, necrotizing pneumonia, PVL has gained much attention as an important virulence factor. However, the extent of its role in pathogenesis is a matter of significant debate and it is likely that other factors, including expression of adhesion proteins such as staphylococcal protein $A$, as well as $\alpha$-toxin and phenol-soluble modulins, are also responsible for increased infection severity $[33,34]$. Regardless, the selection of antibiotics in the treatment of MRSA pneumonia characterized by hemoptysis, leukopenia, high fever, and a cavitary picture on chest radiograph [35] as well as other necrotizing infections may be of clinical significance. Secretory toxin production is likely enhanced by beta-lactams such as nafcillin or oxacillin, maintained by vancomycin, and inhibited, even at sub-inhibitory concentrations, by proteinsynthesis inhibitors, including clindamycin, rifampin, and linezolid [36,37]. As such, it may be reasonable to combine these toxin-suppressing agents with beta-lactams or vancomycin in severe MRSA infections.

\section{Antimicrobial agents for MRSA}

Timely provision of appropriate antimicrobial coverage in an initial anti-infective treatment regimen results in optimal outcomes for bacterial and fungal infections [29,38,39]. This is also true for MRSA infections where it has been shown that antimicrobial regimens not targeting MRSA when it is the cause of serious infection (for example, pneumonia, bacteremia) results in greater mortality and longer lengths of hospitalization [29,30]. The following represents the antimicrobial agents currently available for serious MRSA infections and those in development (Table 1).

\section{Currently available MRSA agents \\ Vancomycin}

Vancomycin has been considered a first-line therapy for invasive MRSA infections as a result of a relatively clean safety profile, durability against resistance development and the lack of other approved alternatives for many years. 
Table 1

Antibiotics currently available for the treatment of serious methicillin-resistant $\mathbf{S}$. aureus infections

\begin{tabular}{|c|c|c|c|c|c|c|}
\hline Antibiotic & Primary indications & Daily dose ${ }^{a}$ & $\begin{array}{l}\text { Volume of } \\
\text { distribution } \\
(\mathrm{L} / \mathrm{kg})\end{array}$ & $\begin{array}{l}\text { Elimination } \\
\text { half-life } \\
\text { (hr) }\end{array}$ & $\begin{array}{l}\text { Protein } \\
\text { binding } \\
(\%)\end{array}$ & Main toxicity \\
\hline Vancomycin & $\begin{array}{l}\text { Pneumonia } \\
\text { Skin/soft tissues } \\
\text { Bacteremia }\end{array}$ & $30 \mathrm{mg} / \mathrm{kg} /$ day & 0.2 to 1.25 & 4 to 6 & 30 to 55 & $\begin{array}{l}\text { Nephrotoxicity (higher doses) } \\
\text { Thrombocytopenia }\end{array}$ \\
\hline \multirow[t]{3}{*}{ Linezolid } & Pneumonia & $600 \mathrm{mg} \mathrm{q} 12 \mathrm{~h}$ & $0.5-0.6$ & 5 & 31 & $\begin{array}{l}\text { Myelosuppression (prolonged } \\
\text { duration generally }>2 \text { weeks) }\end{array}$ \\
\hline & Skin/soft tissues & & & & & $\begin{array}{l}\text { Lactic acidosis } \\
\text { Peripheral and optic } \\
\text { neuropathy }\end{array}$ \\
\hline & & & & & & Serotonin syndrome \\
\hline Tigecycline & $\begin{array}{l}\text { Skin/soft tissues } \\
\text { Intra-abdominal }\end{array}$ & $\begin{array}{l}100 \mathrm{mg} \text { load } \\
50 \mathrm{mg} \mathrm{q} 12 \mathrm{~h}\end{array}$ & 7 to 10 & 37 to 66 & 71 to 89 & $\begin{array}{l}\text { Nausea } \\
\text { Vomiting } \\
\text { Photosensitivity }\end{array}$ \\
\hline Daptomycin & $\begin{array}{l}\text { Bacteremia } \\
\text { Skin/soft tissues }\end{array}$ & $\begin{array}{c}\text { Bacteremia: } 6 \text { mg/kg q } 24 \text { h } \\
\text { Skin/soft tissues: } 4 \text { mg/kg q } 24 \text { h }\end{array}$ & 0.09 & 8 to 9 & 92 & $\begin{array}{l}\text { Muscle toxicity } \\
\text { CPK elevation }\end{array}$ \\
\hline $\begin{array}{l}\text { Quinupristin/ } \\
\text { dalfopristin }\end{array}$ & Skin/soft tissues & $\begin{array}{l}7.5 \mathrm{mg} / \mathrm{kg} \mathrm{q} 8 \mathrm{~h} \\
\text { (via central vein) }\end{array}$ & 0.56 to 0.98 & 0.54 to 1.14 & 11 to 78 & $\begin{array}{l}\text { Phlebitis } \\
\text { Arthralgias and myalgias }\end{array}$ \\
\hline Ceftobiprole ${ }^{b}$ & Skin/soft tissues & $500 \mathrm{mg} \mathrm{q} 8 \mathrm{~h}$ & 0.25 to 0.30 & 3 to 4 & 16 & Allergic reactions \\
\hline Ceftaroline $^{c}$ & $\begin{array}{l}\text { Skin/soft tissues } \\
\text { Pneumonia }\end{array}$ & $600 \mathrm{mg} \mathrm{q} 12 \mathrm{~h}$ & 0.22 to 0.25 & 2.5 to 3 & 18 & Allergic reactions \\
\hline Dalbavancinc & Skin/soft tissues & $\begin{array}{l}1,000 \mathrm{mg} \text { day } 1 \\
500 \mathrm{mg} \text { weekly }\end{array}$ & 0.011 & 147 to 258 & 93 & $\begin{array}{l}\text { Nausea } \\
\text { Vomiting }\end{array}$ \\
\hline Oritavancin ${ }^{\mathrm{c}}$ & Skin/soft tissues & 1.5 to $3 \mathrm{mg} / \mathrm{kg} \mathrm{q} 24 \mathrm{~h}$ & 0.65 to 1.92 & 195 & 90 & $\begin{array}{l}\text { Nausea } \\
\text { Vomiting }\end{array}$ \\
\hline Telavancinc & $\begin{array}{l}\text { Skin/soft tissues } \\
\text { Pneumonia }\end{array}$ & 7.5 to $10 \mathrm{mg} / \mathrm{kg}$ day & 0.1 & 7 to 9 & 93 & Renal thrombocytopenia \\
\hline Iclaprim d & Skin/soft tissues & $0.8 \mathrm{mg} / \mathrm{kg} \mathrm{q} 12 \mathrm{~h}$ & 1.15 & 2.5 to 4.1 & 93 & \\
\hline
\end{tabular}

aDaily dose listed assumes normal kidney and liver function. ${ }^{b}$ Not approved for clinical use in the US. Greater risk of clinical failure in ventilatorassociated pneumonia compared to vancomycin plus ceftazadine. cNot approved for clinical use in the US at the time of writing. dNot approved for clinical use in the US. Failed to demonstrate non-inferiority against linezolid for treatment of complicated skin and skin structure infection. CPK, creatine phosphokinase.

However, increasing concerns about resistance as well as the availability of alternative agents have led to questioning of vancomycin's efficacy in many serious infections. The possible reasons for vancomycin clinical failure are many and include poor penetration into certain tissues [40], loss of accessory gene-regulator function in MRSA [12], and potentially escalating MICs of MRSA to vancomycin [41]. To circumvent the possibility of poor outcomes with vancomycin therapy in MRSA infections with MICs $\geq 1.5 \mathrm{mcg} / \mathrm{ml}$, consensus guidelines recommend a strategy of optimizing the vancomycin pharmacokinetic-pharmacodynamic profile such that trough concentrations of 15 to $20 \mathrm{mcg} / \mathrm{ml}$ are achieved $[42,43]$. Unfortunately, in MRSA infections where vancomycin distribution to the site of infection is limited (for example, lung) it is unlikely that targeted concentrations will be reached [44]. Furthermore, when higher trough concentrations are achieved this may not improve outcome $[45,46]$ and could in fact increase the likelihood of nephrotoxicity [46-48]. The key to successful outcomes then falls to identifying patients at risk for having an MRSA infection with a vancomycin MIC that is $1.5 \mathrm{mcg} / \mathrm{ml}$ or greater and using an alternative agent. Not surprisingly, recent vancomycin 
exposure prior to a suspected or proven MRSA infection, even in a single dose, is a strong predictor of higher vancomycin MICs [49].

\section{Linezolid}

Linezolid is currently approved by the US Food and Drug Administration for the treatment of complicated skin and skin structure infections and nosocomial pneumonia caused by susceptible pathogens, including MRSA. Much debate exists whether linezolid should be considered the drug of choice for MRSA pneumonia on the basis of two retrospective analyses of pooled data from randomized trials comparing linezolid and vancomycin for nosocomial pneumonia [50,51]. In these retrospective analyses, linezolid therapy was associated with increased survival, but one limitation is that vancomycin may have been dosed inadequately, leading to suboptimal concentrations. A randomized, double-blind trial is underway in an effort to either confirm or refute these findings in hospitalized patients with nosocomial pneumonia due to MRSA. Linezolid should also be considered for necrotizing infections, including skin lesions, fasciitis, and pneumonia caused by CA-MRSA as it has been hypothesized that antibiotics with the ability to inhibit protein synthesis may demonstrate efficacy against susceptible toxin-producing strains [36]. Recent guidelines [52] recommend against the use of linezolid as empiric therapy for catheter-related blood stream infections (CRBSIs) as one study [53] comparing vancomycin and linezolid for empiric therapy of complicated skin and soft tissue infections and CRBSI found a trend toward increased mortality in the linezolid group when performing a Kaplan-meier analysis of the intent-to-treat population. In the primary analysis of this study, linezolid was found to be non-inferior to the control group, and a subgroup analysis of patients with MRSA bacteremia showed improved outcomes in the linezolid group [53]. Linezolid is recommended as an alternative agent for CRBSI due to MRSA in this same guideline [52]. Safety concerns that sometimes limit the use of this agent include the association of serotonin toxicity and thrombocytopenia [54].

\section{Tigecycline}

Tigecycline is the first drug approved in the class of glycylcyclines, a derivative of minocycline. A modified side chain on tigecycline enhances binding to the 30s ribosomal subunit, inhibiting protein synthesis and bacterial growth against a broad spectrum of pathogens, including MRSA [55]. Tigecycline is approved in the United States for the treatment of complicated MRSA skin and skin structure infections. The drug is also approved for the treatment of complicated intra-abdominal infections, but for MSSA only. Tigecycline has a large volume of distribution, producing high concentrations in tissues outside of the bloodstream, including bile, colon, and the lung [56]. As a result of serum concentrations that rapidly decline after infusion, caution should be used in patients with proven or suspected bacteremia.
Daptomycin

Daptomycin is indicated for MRSA-associated complicated skin and soft-tissue infections and bloodstream infections, including right-sided endocarditis. Of note, daptomycin should not be used in the treatment of MRSA pneumonia as the drug's activity is inhibited by pulmonary surfactant. As previously mentioned, vancomycin resistance may impact daptomycin susceptibility and the development of reduced daptomycin susceptibility during prolonged treatment of MRSA infections has been reported [16]; these observations should be considered while assessing response to treatment of MRSA infections. As a result of daptomycin's potential to cause myopathy, creatine phosphokinase should be measured at baseline and weekly thereafter.

\section{Quinupristin/dalfopristin}

Quinuprisitn/dalfoprisitin is a combination of two streptogramins, quinupristin and dalfopristin (in a ratio of 30:70 w/w), that inhibit different sites in protein synthesis. Each individual component demonstrates bacteriostatic activity; however, the combination is bactericidal against most Gram-positive organisms. Importantly, while quinupristin/dalfopristin offers activity against MRSA and vancomycin-resistant Enterococcus faecium, it lacks activity against Enterococcus faecalis. Quinuprisitn/dalfoprisitin has US Food and Drug Administration approval for serious infections due to vancomycin-resistant enterococci, and for complicated skin and skin-structure infections. Severe arthralgias and myalgias occur in up to half of patients and, as a result, patient tolerability can limit this agent's utility.

\section{Investigational MRSA agents}

\section{Ceftobiprole}

Ceftobiprole medocaril is a fifth-generation cephalosporin prodrug with a broad spectrum of activity. This agent was designed to maximize binding to PBP2a and yield potent antiMRSA activity [57]. Ceftobiprole is also active against cephalosporin-resistant Streptococcus pneumoniae, ampicillinsensitive E. faecalis, and has a Gram-negative spectrum of activity intermediate between ceftriaxone and cefepime inclusive of Pseudomonas aeruginosa. Two phase III clinical trials have been completed with ceftobiprole for complicated skin and skin structure infections [58,59]. Ceftobiprole was also compared to a combination of ceftazidime plus linezolid for treatment of nosocomial pneumonia. Ceftobiprole was unexpectedly associated with lower cure rates in patients with ventilator-associated pneumonia, particularly in those under age 45 and with high creatinine clearance [60].

\section{Ceftaroline}

Ceftaroline fosamil is also a fifth-generation cephalosporin prodrug, so named due to its spectrum of activity against a broad range of Gram-positive and Gram-negative bacteria. Ceftaroline is active against MRSA due to its enhanced binding to PBP2a compared to other $\beta$-lactam antibiotics [61]. The drug is also active against penicillin- and 
cephalosporin-resistant $S$. pneumoniae, $\beta$-hemolytic streptococci, E. faecalis (variable activity), but has little to no activity against vancomycin-resistant $E$. faecium. Against relevant Gram-negative pathogens, ceftaroline has broad-spectrum activity similar to that of ceftriaxone and the drug is expected to be inactive against Pseudomonas and Acinetobacter spp. [61]. Phase III studies have been conducted for complicated skin and skin structure infections and community-acquired pneumonia, the results of which are pending. Adverse effects in all ceftaroline studies to date have been minor, and include headache, nausea, insomnia, and abnormal body odor [62].

\section{Dalbavancin}

Dalbavancin is an investigational lipoglycopeptide with a bactericidal mechanism of action similar to other glycopeptides in that it complexes with the D-alanyl-D-alanine (D-AlaD-Ala) terminal of peptidoglycan and inhibits transglycosylation and transpeptidation. Like teicoplanin, dalbavancin possesses a lipophilic side chain that leads to both high protein binding and an extended half-life, which allows for a unique once-weekly dosing of the drug [63]. Dalbavancin is more potent than vancomycin against staphylococci, and is highly active against both MSSA and MRSA. Dalbavancin is also active against VISA, although $\mathrm{MIC}_{90}$ ranges are higher at 1 to $2 \mathrm{mcg} / \mathrm{ml}$. However, dalbavancin is not active against enterococci with the VanA phenotype [64]. Clinical data for dalbavancin include phase II and III trials in both uncomplicated and complicated skin and skin structure infections, and catheter-related bloodstream infections. Dalbavancin has been well-tolerated throughout clinical trials, with the most commonly seen adverse effects being fever, headache, and nausea.

\section{Oritavancin}

Oritavancin, another investigational glycopeptide, contains novel structural modifications that allow it to dimerize and anchor itself in the bacterial membrane. These modifications also confer an enhanced spectrum of activity over traditional glycopeptide antibiotics [65]. Ortivancin has similar in vitro activity as vancomycin against staphylococci and is equipotent against both MSSA and MRSA. It also has activity against VISA and VRSA, but MICs are increased to $1 \mathrm{mg} / \mathrm{L}$ and $0.5 \mathrm{mg} / \mathrm{L}$, respectively [66]. Oritivancin is active against enterococci, including vancomycin-resistant enterococci; however, MICs are significantly higher for vancomycinresistant enterococci versus vancomycin-sensitive strains.

\section{Telavancin}

Telavancin is an investigational glycopeptide derivative of vancomycin. Like oritavancin, telavancin has the ability to anchor itself in the bacterial membrane, which disrupts polymerization and crosslinking of peptidoglycan. Telavancin also interferes with the normal function of the bacterial membrane, leading to a decrease in the barrier function of the membrane. This dual mechanism helps to explain its high potency and rapid bactericidal activity [60]. Telavancin is
This article is part of a review series on Infection, edited by Steven Opal.

Other articles in the series can be found online at http://ccforum.com/articles/ theme-series.asp?series=CC_Infection

bactericidal against staphylococci, including MRSA, VISA, and VRSA, with $\mathrm{MIC}_{90}$ ranges of 0.25 to $1,0.5$ to 2 , and 2 to $4 \mathrm{mg} / \mathrm{L}$, respectively [67]. Telavancin, like oritavancin, is potent against both penicillin-susceptible and -resistant strains of $S$. pneumoniae. Telavancin is also active against vancomycin-susceptible E. faecium and E. faecalis. Two identical skin and skin structure trials, ATLAS I and II, compared telavancin $10 \mathrm{mg} / \mathrm{kg} /$ day to vancomycin $1 \mathrm{~g}$ every 12 hours and found telavancin to be non-inferior to vancomycin [63]. Telavancin has also been studied in hospitalacquired pneumonia.

\section{Iclaprim}

Iclaprim (formerly AR-100 and Ro 48-2622) is an investigational intravenous diaminopyrimidine antibacterial agent that, like trimethoprim, selectively inhibits dihydrofolate reductase of both Gram-positive and Gram-negative bacteria and exerts bactericidal effects [68]. Iclaprim is active against MSSA, community- and nosocomial-MRSA, VISA, VRSA, groups $A$ and $B$ streptococci, and pneumococci, and is variably active against enterococci $[69,70]$. Iclaprim appears to have similar Gram-negative activity to that of trimethoprim, including activity against Escherichia coli, Klebsiella pneumoniae, Enterobacter, Citrobacter freundii, and Proteus vulgaris. Iclaprim also appears to have activity against the atypical respiratory pathogens Legionella and Chlamydia pneumoniae, but is not active against $P$. aeruginosa or anaerobes [69].

\section{Conclusion}

MRSA will continue to be an important infection in the ICU setting for the foreseeable future. Clinicians should be aware of the changing virulence patterns and antimicrobial susceptibility patterns of MRSA in their local areas. This information should be used to develop prevention and treatment strategies aimed at minimizing patient morbidity and healthcare costs related to MRSA infections.

\section{Competing interests}

$\mathrm{MHK}$ is on the speakers bureau for the following companies: Pfizer, Bard, Merck, Astrazeneca. MHK is a consultant for the following companies: Pfizer, Bard, Astellas, Orthno-McNeil. LS and SM have no competing interests to report.

\section{Acknowledgements}

MHK's effort was supported by the Barnes-Jewish Hospital foundation. 


\section{References}

1. Chambers HF: Methicillin resistance in staphylococci: molecular and biochemical basis and clinical implications. Clin Microbiol Rev 1997, 10:781-791.

2. Zhang K, McClure J, Elsayed S, Conly JM: Novel staphylococcal cassette chromosome mec type, tentatively designated type VIII, harboring class A mec and type $4 \mathrm{ccr}$ gene complexes in a Canadian epidemic strain of methicillin-resistant Staphylococcus aureus. Antimicrob Agents Chemother 2009, 53:531-540.

3. McDougal LK, Steward CD, Killgore GE, Chaitram JM, McAllister SK, Tenover FC: Pulsed-field gel electrophoresis typing of oxacillin-resistant Staphylococcus aureus isolates from the united states: establishing a national database. J Clin Microbiol 2003, 41:5113-5120.

4. Popovich KJ, Weinstein RA, Hota B: Are community-associated methicillin-resistant Staphylococcus aureus (MRSA) strains replacing traditional nosocomial MRSA strains? Clin Infect Dis 2008, 46:787-794.

5. Schramm GE, Johnson JA, Doherty JA, Micek ST, Kollef MH: Increasing incidence of sterile-site infections due to non-multidrug-resistant, oxacillin-resistant Staphylococcus aureus among hospitalized patients. Infect Control Hosp Epidemiol 2007, 28:95-97.

6. Davis SL, Rybak MJ, Amjad M, Kaatz GW, McKinnon PS: Characteristics of patients with healthcare-associated infection due to SCCmec type IV methicillin-resistant Staphylococcus aureus. Infect Control Hosp Epidemiol 2006, 27:1025-1031.

7. Seybold U, Kourbatova EV, Johnson JG, Halvosa SJ, Wang YF, King MD, Ray SM, Blumberg HM: Emergence of communityassociated methicillin-resistant Staphylococcus aureus USA300 genotype as a major cause of health care-associated blood stream infections. Clin Infect Dis 2006, 42:647656.

8. Naimi TS, LeDell KH, Como-Sabetti K, Borchardt SM, Boxrud DJ, Etienne J, Johnson SK, Vandenesch F, Fridkin S, O'Boyle C, Danila RN, Lynfield R: Comparison of community- and health care-associated methicillin-resistant Staphylococcus aureus infection. JAMA 2003, 290:2976-2984.

9. Fridkin SK, Hageman JC, Morrison M, Sanza LT, Como-Sabetti K, Jernigan JA, Harriman K, Harrison LH, Lynfield R, Farley MM; Active Bacterial Core Surveillance Program of the Emerging Infections Program Network: Methicillin-resistant Staphylococcus aureus disease in three communities. N Engl J Med 2005, 352:1436-1444.

10. Courvalin $\mathrm{P}$ : Vancomycin resistance in gram-positive cocci. Clin Infect Dis 2006, 42(Suppl 1):S25-34.

11. Liu C, Chambers HFL: Staphylococcal aureus with heterogeneous resistance to vancoycin: epidemiology, clinical significance, and critical assessment of diagnostic methods. Antimicrob Agents Chemother 2003, 47:3040-3045.

12. Sakoulas G, Eliopoulos GM, Moellering RC Jr, Wennersten C, Venkataraman L, Novick RP, Gold HS: Accessory gene regulator (agr) locus in geographically diverse Staphylococcus aureus isolates with reduced susceptibility to vancomycin. Antimicrob Agents Chemother 2002, 46:1492-1502.

13. Hayden MK, Rezai K, Hayes RA, Lolans K, Quinn JP, Weinstein $\mathrm{RA}$ : Development of daptomycin resistance in vivo in methicillin resistant Staphylococcal aureus. J Clin Microbiol 2005, 43:5285-5287.

14. Vikram HR, Havill NL, Koeth LM, Boyce JM: Clinical progression of methicillin-resistant Staphylococcus aureus vertebral osteomyelitis with reduced susceptibility to daptomycin. J Clin Microbiol 2005, 43:5384-5387.

15. Kirby A, Mohandas K, Broughton C, Neal TJ, Smith GW, Pai P, Nistal de Paz C: In vivo development of heterogeneous glycopeptide-intermediate staphylococcus aureus (hGISA), GISA and daptomycin resistance in a patient with methicillinresistant S. aureus endocarditis. J Med Microbiol 2009, 58: 376-380.

16. Fowler VG Jr, Boucher HW, Corey GR, Abrutyn E, Karchmer AW, Rupp ME, Levine DP, Chambers HF, Tally FP, Vigliani GA, Cabell $\mathrm{CH}$, Link AS, DeMeyer I, Filler SG, Zervos M, Cook P, Parsonnet J, Bernstein JM, Price CS, Forrest GN, Fätkenheuer G, Gareca M, Rehm SJ, Brodt HR, Tice A, Cosgrove SE; S. aureus Endocarditis and Bacteremia Study Group: Daptomycin versus standard therapy for bacteremia and endocarditis caused by Staphylococcus aureus. N Engl J Med 2006, 355:653-665.
17. Sharma M, Riederer K, Chase $P$, Khatib R: High rate of decreasing daptomycin susceptibility during the treatment of persistent Staphylococcus aureus bacteremia. Eur J Clin Microbiol Infect Dis 2008, 27:433-437.

18. Tsiodras S, Gold HS, Sakoulas G, Eliopoulos GM, Wennersten C, Venkataraman L, Moellering RC, Ferraro MJ: Linezolid resistance in a clinical isolate of Staphylococcus aureus. Lancet 2001, 358:207-208.

19. Peeters MJ, Sarria JC: Clinical characteristics of linezolidresistant Staphylococcus aureus infections. Am J Med Sci 2005, 330:102-104.

20. Malbruny B, Canu A, Bozdogan B, Fantin B, Zarrouk V, DutkaMalen S, Feger C, Leclercq R: Resistance to quinupristin-dalfopristin due to mutation of L22 ribosomal protein in Staphylococcus aureus. Antimicrob Agents Chemother 2002 46:2200-2207.

21. Lowy FD: Staphylococcus aureus infections. $N$ Engl J Med 1998, 339:520-532.

22. Foster TJ: Immune evasion by staphylococci. Nat Rev Microbiol 2005, 3:948-958.

23. Sakoulas G: The accessory gene regulator (agr) in methicillinresistant Staphylococcus aureus: role in virulence and reduced susceptibility to glycopeptide antibiotics. Drug Discov Today 2006, 3:287-294.

24. Tsuji BT, Rybak MJ, Cheung CM, Amjad M, Kaatz GW: Community- and health care-associated methicillin-resistant Staphylococcus aureus: a comparison of molecular epidemiology and antimicrobial activities of various agents. Diagn Microbiol Infect Dis 2007, 58:41-47.

25. Loughman JA, Fritz SA, Storch GA, Hunstad DA: Virulence gene expression in human community-acquired Staphylococcus aureus infection. J Infect Dis 2009, 199:294-301.

26. Klevens RM, Morrison MA, Nadle J, Petit S, Gershman K, Ray S, Harrison LH, Lynfield R, Dumyati G, Townes JM, Craig AS, Zell ER, Fosheim GE, McDougal LK, Carey RB, Fridkin SK; Active Bacterial Core surveillance (ABCs) MRSA Investigators: Invasive methicillin-resistant Staphylococcus aureus infections in the United States. JAMA 2007, 298:1763-1771

27. Cosgrove SE, Carmeli $\mathrm{Y}$ : The impact of antimicrobial resistance on health and economic outcomes. Clin Infect Dis 2003, 36:1433-1437.

28. Shurland S, Zhan M, Bradham DD, Roghmann MC: Comparison of mortality risk associated with bacteremia due to methicillin-resistant and methicillin-susceptible Staphylococcus aureus. Infect Control Hosp Epidemiol 2007, 28:273-279.

29. Schramm GE, Johnson JA, Doherty JA, Micek ST, Kollef MH: Methicillin-resistant Staphylococcus aureus sterile-site infection: The importance of appropriate initial antimicrobial treatment. Crit Care Med 2006, 34:2069-2074.

30. Shorr AF, Micek ST, Kollef MH: Inappropriate therapy for methicillin-resistant Staphylococcus aureus: resource utilization and cost implications. Crit Care Med 2008, 36:2335-2340.

31. Lodise TP, Graves J, Evans A, Graffunder E, Helmecke M, Lomaestro BM, Stellrecht K: Relationship between vancomycin MIC and failure among patients with methicillin-resistant Staphylococcus aureus bacteremia treated with vancomycin. Antimicrob Agents Chemother 2008, 52:3315-3320.

32. Soriano A, Marco F, Martínez JA, Pisos E, Almela M, Dimova VP, Alamo D, Ortega M, Lopez J, Mensa J: Influence of vancomycin minimum inhibitory concentration on the treatment of methicillin-resistant Staphylococcus aureus bacteremia. Clin Infect Dis 2008, 46:193-200.

33. Labandeira-Rey M, Couzon F, Boisset S, Brown EL, Bes M, Benito Y, Barbu EM, Vazquez V, Höök M, Etienne J, Vandenesch F, Bowden MG: Staphylococcus aureus Panton-Valentine leukocidin causes necrotizing pneumonia. Science 2007, 315: 1130-1133.

34. Li M, Diep BA, Villaruz AE, Braughton KR, Jiang X, DeLeo FR, Chamber HF, Lu Y, Otto M: Evaluation of virulence in epidemic community-associated methicillin-resistant Staphylococcus aureus. Proc Natl Acad Sci USA 2009, 103:5883-5888.

35. Gillet $Y$, Etienne J, Lina G, Vandenesch F: Association of necrotizing pneumonia with panton-valentine leukocidin-producing Staphylococcus aureus, regardless of methicillin resistance. Clin Infect Dis 2008, 47:985-986.

36. Stevens DL, Ma Y, Salmi DB, Mclndoo E, Wallace RJ, Bryant AE: Impact of antibiotics on expression of virulence-associated 
exotoxin genes in methicillin-sensitive and methicillin-resistant Staphylococcus aureus. J Infect Dis 2007, 195:202-211.

37. Dumitrescu O, Badiou C, Bes M, Reverdy ME, Vandenesch F, Etienne J, Lina G: Effect of antibiotics, alone and in combination, on Panton-Valentine leukocidin production by a Staphylococcus aureus reference strain. Clin Micro Infect 2008, 14: 384-388.

38. Kollef MH, Sherman G, Ward S, Fraser VJ: Inadequate antimicrobial treatment of infections: a risk factor for hospital mortality among critically ill patients. Chest 1999, 115:462-474.

39. Morrell M, Fraser VJ, Kollef MH: Delaying the empiric treatment of Candida bloodstream infection until positive blood culture results are obtained: a potential risk factor for hospital mortality. Antimicrob Agents Chemother 2005, 49:3640-3665.

40. Cruciani M, Gatti G, Lazzarini L, Furlan G, Broccali G, Malena M, Franchini $C$, Concia E: Penetration of vancomycin into human lung tissue. J Antimicrob Chemother 1996, 38:865-869.

41. Robert J, Bismuth R, Jarlier V: Decreased susceptibility to glycopeptides in methicillin-resistant Staphylococcus aureus: a 20 year study in a large French teaching hospital, 1983-2002. $J$ Antimicrob Chemother 2006, 57:506-510.

42. American Thoracic Society: Guidelines for the management of adults with hospital-acquired, ventilator-associated, and healthcare-associated pneumonia. Am J Respir Crit Care Med 2005, 171:388-416.

43. Rybak M, Lomaestro B, Rotschafer JC, Moellering R Jr, Craig W, Billeter M, Dalovisio JR, Levine DP: Therapeutic monitoring of vancomycin in adult patients: A consensus review of the American Society of Health-System Pharmacists, the Infectious Diseases Society of America, and the Society of Infectious Diseases Pharmacists. Am J Health Syst Pharm 2009, 66:82-98

44. Mohr JF, Murray BE: Point: Vancomycin is not obsolete for the treatment of infection caused by methicillin-resistant Staphylococcus aureus. Clin Infect Dis 2007, 44:1536-1542.

45. Jeffres MN, Isakow W, Doherty JA, McKinnon PS, Ritchie DJ, Micek ST, Kollef MH: Predictors of mortality for methicillinresistant Staphylococcus aureus health-care-associated pneumonia: specific evaluation of vancomycin pharmacokinetic indices. Chest 2006,130:947-955.

46. Hidayat LK, Hsu DI, Quist R, Shriner KA, Wong-Beringer A: Highdose vancomycin therapy for methicillin-resistant Staphylococcus aureus infections: efficacy and toxicity. Arch Intern Med 2006,166:2138-2144

47. Jeffres MN, Isakow W, Doherty JA, Micek ST, Kollef MH: A retrospective analysis of possible renal toxicity associated with vancomycin in patients with health care-associated methicillin-resistant Staphylococcus aureus pneumonia. Clin Ther 2007, 29:1107-1115.

48. Lodise TP, Lomaestro B, Graves J, Drusano GL: Larger vancomycin doses (at least four grams per day) are associated with an increased incidence of nephrotoxicity. Antimicrob Agents Chemother 2008, 52:1330-1336.

49. Moise PA, Smyth DS, El-Fawal N, Robinson DA, Holden PN, Forrest A, Sakoulas G: Microbiological effects of prior vancomycin use in patients with methicillin-resistant Staphylococcus aureus bacteraemia. J Antimicrob Chemother 2008, 61: 85-90.

50. Wunderink RG, Rello J, Cammarata SK, Croos-Dabrera RV, Kollef $\mathrm{MH}$ : Linezolid vs vancomycin: analysis of two double-blind studies of patients with methicillin-resistant Staphylococcus aureus nosocomial pneumonia. Chest 2003, 124:1789-1797.

51. Kollef MH, Rello J, Cammarata SK, Croos-Dabrera RV, Wunderink RG: Clinical cure and survival in Gram-positive ventilatorassociated pneumonia: retrospective analysis of two doubleblind studies comparing linezolid with vancomycin. Intensive Care Med 2004, 30:388-394

52. Mermel LA, Allon M, Bouza E, Craven DE, Flynn P, O'Grady NP, Raad II, Rijnders BJ, Sherertz RJ, Warren DK: Clinical practice guidelines for the diagnosis and management of intravascular catheter-related infection: 2009 update by the Infectious Diseases Society of America. Clin Infect Dis 2009, 49:1-45.

53. Wilcox MH, Tack KJ, Bouza E, Herr DL, Ruf BR, ljzerman MM, Croos-Dabrera RV, Kunkel MJ, Knirsch C: Complicated skin and skin-structure infections and catheter-related blood stream infections: noninferiority of linezolid in a phase 3 study. Clin Infect Dis 2009, 48:203-212.
54. Taylor JJ, Wilson JW, Estes LL: Linezolid and serotonergic drug interactions: a retrospective survey. Clin Infect Dis 2006, 43: 80-87.

55. Rose WE, Rybak MJ: Tigecycline: first of a new class of antimicrobial agents. Pharmacotherapy 2006, 26:1099-1110.

56. Rodvold KA, Gotfried MH, Cwik M, Korth-Bradley JM, Dukart G Ellis-Grosse E: Serum, tissue and body fluid concentrations of tigecycline after a single $100 \mathrm{mg}$ dose. J Antimicrob Chemother 2006, 58:1221-1229.

57. Vidaillac C, Rybak MJ: Ceftobiprole: First cephalosporin with activity against methicillin-resistant Staphylococcus aureus. Pharmacotherapy 2009, 29:511-525.

58. Noel GJ, Strauss RS, Amsler K, Heep M, Pypstra R, Solomkin JS: Results of a double-blind, randomized trial of ceftobiprole treatment of complicated skin and skin structure infections caused by gram-positive bacteria. Antimicrob Agents Chemother 2008, 52:37-44.

59. Noel GJ, Bush K, Bagchi P, lanus J, Strauss RS: A randomized, double-blind trial comparing ceftobiprole medocaril with vancomycin plus ceftazidime for the treatment of patients with complicated skin and skin structure infections. Clin Infect Dis 2008, 46:647-655

60. Noel GJ, Strauss RS, Shah A, Bagchi P: Ceftobiprole versus ceftazidime combined with linezolid for treatment of patients with nosocomial pneumonia [abstract]. In Proceedings of the $48^{\text {th }}$ Annual Interscience Conference on Antimicrobial Agents and Chemotherapy; 25-28 October 2008; Washington, DC. 2008:K-486.

61. Ge Y, Biek D, Talbot GH, Sahm DF: In vitro profiling of ceftaroline against a collection of recent bacterial clinical isolates from across the United States. Antimicrob Agents Chemother 2008, 52:3398-3407.

62. Talbot GH, Thye D, Das A, Ge Y: Phase 2 study of ceftaroline versus standard therapy in the treatment of complicated skin and skin structure infections. Antimicrob Agents Chemother 2007, 51:3612-3616.

63. Zhanel GG, Trapp S, Gin AS, DeCorby M, Lagacé-Wiens PR, Rubinstein E, Hoban DJ, Karlowsky JA: Dalbavancin and telavancin: novel lipoglycopeptides for the treatment of Grampositive infections. Expert Rev Ant Infect Ther 2008, 6:67-81.

64. Goldstein BP, Draghi DC, Sheehan DJ, Hogan P, Sahm DF: Bactericidal activity and resistance development profiling of dalbavancin. Antimicrob Agents Chemother 2007, 51:1150-1154.

65. Mercier R-C, Hrebickova L: Oritavancin: a new avenue for resistant gram-positive bacteria. Expert Rev Anti Infect Ther 2005, 3:325-332.

66. Tenover FC, Lancaster MV, Hill BC, Steward CD, Stocker SA Hancock GA, O'Hara CM, McAllister SK, Clark NC, Hiramatsu K: Characterization of staphylococci with reduced susceptibilities to vancomycin and other glycopeptides. J Clin Microbiol 1998, 36:1020-1027.

67. Leuthner KD, Cheung CM, Rybak MJ: Comparative activity of the new lipoglycopeptide telavancin in the presence and absence of serum against $\mathbf{5 0}$ glycopeptide non-susceptible staphylococci and three vancomycin-resistant Staphylococcus aureus. J Antimicrob Chemother 2006, 58:338-343.

68. Schneider P, Hawser S, Islam K: Iclaprim, a novel diaminopyrimidine with potent activity on trimethoprim sensitive and resistant bacteria. Bioorg Med Chem Lett 2003, 13:4217-4721.

69. Laue H, Weiss L, Bernardi A, Hawser S, Lociuro S, Islam K: In vitro activity of the novel diaminopyrimidine, iclaprim, in combination with folate inhibitors and other antimicrobials with different mechanisms of action. J Antimicrob Chemother 2007, 60:1391-1394.

70. Bozdogan B, Esel D, Whitener C, Browne FA, Appelbaum PC: Antibacterial susceptibility of a vancomycin-resistant Staphylococcus aureus strain isolated at the Hershey Medical Center. J Antimicrob Chemother 2003, 52:864-868. 